\title{
Review
}

Journal of Innate

Immunity

\section{New Insights into the Regulation of Signalling by Toll-Like Receptors and Nod-Like Receptors}

\author{
Rebecca C. Coll Luke A.J. O'Neill \\ School of Biochemistry and Immunology, Trinity College Dublin, Dublin, Ireland
}

\section{Key Words}

miRNA - Negative regulation - Nod-like receptor · Toll-like receptor - Ubiquitination

\begin{abstract}
The activation of Toll-Like receptors (TLRs) and Nod-like receptors (NLRs) triggers intracellular signalling pathways that lead to effector mechanisms in innate immunity and inflammation. The negative regulation of TLR signalling has been extensively studied. Current areas of research include posttranscriptional regulation by miRNA, post-translational regulation by ubiquitination and regulation by splice variants such as MyD88s, TRAM adaptor with GOLD domain and IRAK2 isoforms. The negative regulation of NLR signalling is a relatively new area of research. Examples include a splice variant of NOD2, the ubiquitin editing enzyme A20, pyrin domain-only proteins and caspase recruitment domain-only proteins which all have a negative effect on NOD2 or NLRP3 signalling. A greater understanding of the mechanisms underlying the negative control of TLR and NLR signalling may provide new targets for therapeutic intervention.
\end{abstract}

Copyright $\odot 2010$ S. Karger AG, Basel
(C) 2010 S. Karger AG, Basel

1662-811X/10/0025-0406\$26.00/0

Fax +4161306 1234

E-Mail karger@karger.ch

www.karger.com
Accessible online at: www.karger.com/jin
The innate immune response is initiated through the activation of pattern recognition receptors (PRRs) by pathogenic or endogenous motifs. The signalling pathways initiated by these receptors shape both the initial innate response and the subsequent adaptive immune response. PRR signalling needs to be tightly regulated, as excessive or uncontrolled signalling can cause damaging inflammation to the host. A complex system of negative regulation has evolved to keep PRR signalling in check. Toll-like receptor (TLR) signalling is subject to extensive negative regulation through extracellular and intracellular mechanisms that have been thoroughly reviewed [1]. Nod-like receptors (NLRs) are a second family of PRR that have been the subject of intensive research in recent years. The negative regulation of NLR function is an emerging area. Here we will review recent findings in the field of negative regulation of both TLRs and NLRs. These insights are providing new information into the control of innate immunity and also into the pathogenesis of infections and inflammatory diseases. 


\section{Regulation of TLR Signalling by miRNA}

Post-transcriptional regulation of inflammatory signalling pathways is an emerging area of research. In particular, the recently identified class of non-coding small RNA molecules known as miRNA have been the subject of intensive study. miRNA are evolutionarily conserved, single-stranded, 18-24 nucleotide long RNA molecules that bind to complementary sites in the $3^{\prime}$ untranslated region ( $3^{\prime} \mathrm{UTR}$ ) of their specific target mRNA. This binding event causes mRNA destabilisation and repression of translation, leading to a significant reduction in protein level [2]. This regulation system is both wide-ranging and complex. An individual mRNA strand can be regulated by multiple miRNA, whilst a miRNA can potentially target up to 100 mRNAs. Over 700 miRNA coding genes have been identified in the human genome with around 100 of these being expressed in the immune system [3]. miRNA are involved in the development and function of both the innate and adaptive immune systems. Myeloid cell development and $\mathrm{T}$ and $\mathrm{B}$ cell differentiation are all influenced by miRNA as are the function of the mature cell types. Aberrant expression of miRNA has been implicated in the pathogenesis of immunologically related cancers and may influence the development of autoimmunity [3]. miRNA often act as negative feedback regulators and recent studies have highlighted the role miRNA play in the regulation of immune cell signalling and inflammation.

miRNA influence the resolution and control of inflammation at a number of different levels. They control the expression of proteins involved in pro-inflammatory signalling, negative regulators of pro-inflammatory signalling and initiators of anti-inflammatory signalling. The targets of miRNA regulation in TLR signalling are illustrated in figure 1 .

\section{$\operatorname{miR}-155$}

miR-155 was one of the first miRNAs implicated in the immune response and is one of the most extensively studied miRNA. A number of miR-155 targets are involved in the innate immune response. However, the role of miR155 is complicated by differences in cell type-specific expression and function. miR-155 expression in macrophages is induced by a number of pro-inflammatory stimuli such as lipopolysaccharide (LPS), poly(I:C) and interferons $[4,5]$. A recent study by Ceppi et al. [6] also showed miR-155 induction in response to LPS in human monocyte-derived dendritic cells (MDDCs). The authors analysed differences in microarray data from LPS-acti- vated MDDCs transfected with a control scrambled or a miR-155 silencing oligonucleotide. They identified the p38 mitogen-activated protein kinase (MAPK) and IL-1/ TLR signalling pathways as potential targets of miR-155 regulation. TGF $\beta$-activated kinase 1 (TAK1)-binding protein 2 (TAB2) was identified as a direct target of miR-155. Transfection of anti-miR-155 increased TAB2 protein expression in MDDCs. While in HEK293T cells co-transfection of miR-155 and a luciferase reporter vector with the 3'UTR of TAB2 inhibited luciferase activity relative to control miRNA. TAB2 is a part of the signalling complex that activates TAK1 and downstream MAPK and NFкB pathways in IL-1/TLR signalling. Thus in MDDCs, LPSinduced miR-155 may negatively regulate pro-inflammatory signalling by inhibiting TAB2 expression.

Other reports have, however, implicated miR-155 as a positive regulator of inflammation. Transgenic mice that overexpress miR-155 were shown to have elevated levels of TNF $\alpha$ in response to LPS stimulation and to be hypersensitive to a model of LPS-induced shock [7]. miR-155 has been shown to inhibit the expression of suppressor of cytokine signalling 1 (SOCS1) in both regulatory $\mathrm{T}$ cells and macrophages $[8,9]$. SOCS1 is a negative regulator of TLR signalling [10]. Androulidaki et al. [9] have demonstrated that the serine threonine kinase Akt negatively regulates miR-155 expression. LPS-induced miR-155 expression was increased in Akt1-deficient macrophages and expression of constitutively active Akt1 suppressed basal and LPS stimulated levels of miR-155. SOCS1 expression in response to LPS stimulation was reduced in Akt1-deficient macrophages relative to wild-type controls. Inhibition of miR-155 enhanced SOCS1 expression basally and in response to LPS. Thus, Aktl suppresses miR-155 which is an inhibitor of SOCS1 expression required for attenuating TLR signalling. The authors also showed that Akt1-deficient macrophages are hyperresponsive to LPS. This increased response is in part mediated by miR-155, as inhibition of miR-155 in Akt1-deficient cells increases SOCS1 expression and decreases $\mathrm{TNF} \alpha$ and IL-6 production relative to Akt1-deficient cells transfected with a scrambled miRNA [9]. Recently, miR-155 was also shown to regulate the expression of the inositol phosphatase SHIP1 [11]. SHIP1 activity was previously shown to be involved in the induction of tolerance to LPS. SHIP1 levels are increased by TGF $\beta$ secreted in response to LPS but SHIP1-deficient mice do not display tolerance [12]. miR-155-deficient macrophages have increased levels of SHIP1 expression in response to LPS stimulation. In this context miR-155 would suppress the induction of tolerance and promote inflammation. 


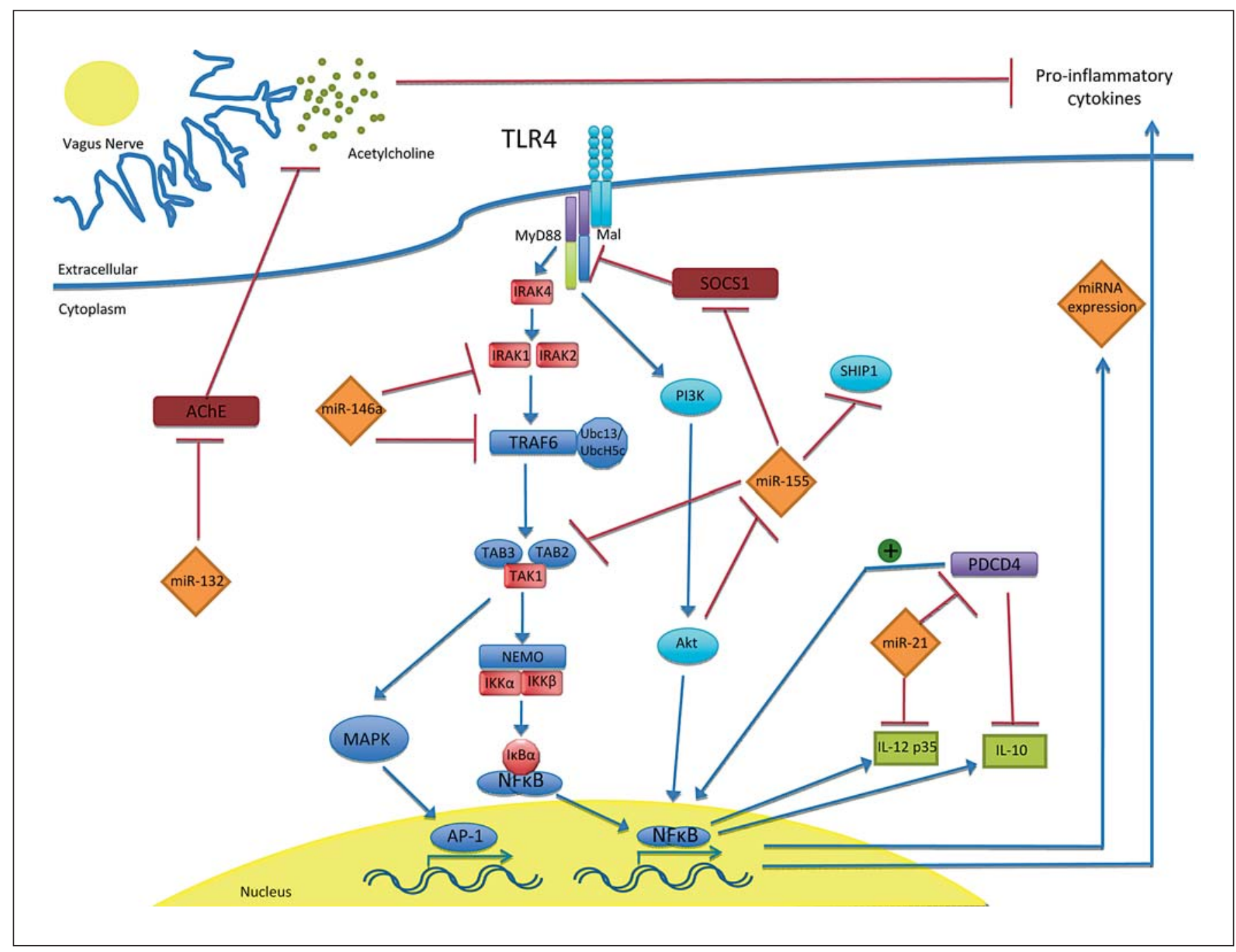

Fig. 1. Regulation of TLR signalling by miRNA. TLR4 ligand binding induces dimerisation and recruitment of the bridging adaptor MyD88 adaptor like (Mal), which binds myeloid differentiation primary response protein 88 (MyD88). MyD88 recruits and activates the serine/threonine kinase IL-1 receptor associated kinase 4 (IRAK4), which phosphorylates IRAK1 and activates IRAK2. The activated IRAKs associate with tumour necrosis factor receptor-associated factor 6 (TRAF6), an E3 ubiquitin ligase enzyme. TRAF6 Lys ${ }^{63}$ polyubiquitinates itself using an E2 ubiquitin-conjugating complex containing $\mathrm{Ubc1} 3$ or $\mathrm{UbcH} 5 \mathrm{c}$. TGF $\beta$ activated kinase 1 (TAK1)-binding proteins TAB2 and TAB3 recognise TRAF6 and help recruit TGF $\beta$-activated kinase 1 (TAK1). TAK1 activates the IкB Kinase (IKK) complex. IKK phosphorylates inhibitor of NFKB (IкB) proteins, which are then polyubiquitinated and degraded by the proteasome. This allows $\mathrm{NF} \kappa \mathrm{B}$ dimers to translocate to the nucleus where they activate transcription of numerous targets genes including pro-inflammatory cytokines. TAK1 also activates the mitogen activated protein kinases (MAPKs), which control the transcription factor activator protein 1 (AP-1). MyD88 activates phosphoinositide 3-ki- nase (PI3K), which activates the kinase Akt resulting in NFкB activation. NFкB activation induces the expression of miR-155, miR-146a, miR-132 and miR-21. In the cholinergic anti-inflammatory response, vagus nerves release acetylcholine, which decreases pro-inflammatory cytokine production. Acetylcholine is hydrolysed by AChE but miR-132 inhibits expression of AChE, thus promoting the cholinergic response. miR-146a negatively regulates the expression of IRAK1, IRAK2 and TRAF6, which attenuates NFKB activation. miR-21 negatively regulates pro-inflammatory signaling by inhibiting the expression of IL-12 p35, a subunit of the pro-inflammatory cytokine IL-12. miR-21 also negatively regulates the expression of $\mathrm{PDCD} 4$, a positive regulator of NFкB activation, which functions to suppress the expression of the anti-inflammatory cytokine IL-10. miR-155 inhibits the expression of TAB2, which attenuates NFKB activation. However, miR-155 also targets SOCS1, a negative regulator of Mal and SHIP1, which is involved in the induction of tolerance. Akt inhibits the expression of miR-155. Thus, miR-155 can also positively regulate TLR signalling. 
Whether miR-155 is a negative or positive regulator of TLR signalling therefore requires clarification.

\section{miR-146a}

Initial studies on miR-146a showed that its expression is NFKB-dependent and can be induced by TLR4, TLR2, TLR 5, IL-1 $\beta$ and TNF $\alpha$ [13]. It was also shown that miR146 a could regulate the expression of the signalling molecules IL-1 receptor-associated kinase 1 (IRAK1) and tumour necrosis factor receptor-associated factor 6 (TRAF6) [13]. A recent study has shown that miR-146a can also be induced through RIG-1-dependent NFкB activation by vesicular stomatitis virus (VSV) [14]. miR146 a was shown to negatively regulate VSV-induced type 1 interferon production, and also inhibited VSV-induced production of the pro-inflammatory mediators IL-1 $\beta$, IL-6, TNF $\alpha$, IL-8 and RANTES in macrophages. Knockdown of the miR-146a targets IRAK1, IRAK2 and TRAF6 using siRNA also reduced VSV stimulated type 1 interferon production in murine macrophages. Another recent study also identified a role for miR-146a in regulating type-1 interferon responses [15]. The authors found that miR-146a expression was reduced in the peripheral blood leukocytes of systemic lupus erythematosus patients. They also observed a negative correlation between low miR-146a expression and increased type-1 interferon pathway activation. Further investigations showed that overexpression of miR-146a in peripheral blood mononuclear cells (PBMCs) inhibited IFN $\alpha$ and IFN $\beta$ in response to TLR7 stimulation, whereas knockdown of endogenous miR-146a increased interferon production [15]. Together, these studies establish a clear role for miR-146a as a negative regulator of type-1 interferon production in both TLR and RIG-1 signalling. A study by Nahid et al. [16] examined the involvement of miRNA in LPS-induced tolerance in the THP-1 human monocytic cell line. The authors examined the kinetics of LPS-induced TNF $\alpha$ secretion and mRNA levels relative to the expression of a number of miRNA. They found that at later time points miR-146a was highly induced. In a model of tolerance where cells were primed with LPS before a second LPS challenge, miR-146a was potently induced in the tolerised cells. The high levels of miR-146a correlated with decreased TNF $\alpha$, TRAF6 and IRAK1 expression in tolerised cells. Overexpression of miR-146a inhibited TNF $\alpha$, IL-1 $\beta$ and IL- 6 secretion in response to LPS and also decreased TRAF- 6 and IRAK1 expression. Conversely, inhibition of miR-146a increased $\mathrm{TNF} \alpha$ secretion and TRAF6 and IRAK1 expression in tolerised cells [16]. This study confirms that miR-146a negatively regulates TLR4- induced pro-inflammatory signalling by decreasing the expression of IRAK1 and TRAF6. It also shows that miR$146 \mathrm{a}$ activity is involved in suppressing the pro-inflammatory response of THP-1 cells that are tolerised to LPS.

\section{miR-21}

Deregulated expression of miR-21 has been frequently found in numerous cancers, leading to its classification as an 'onco-miR' [17]. Besides its oncogenic functions, recent investigations have also implicated the involvement of miR-21 in inflammation. A microarray screen carried out to examine miRNA expression in a murine model of allergic asthma found that miR-21 was highly induced [18]. This induction was confirmed in two other models of asthma, where high miR-21 expression was found in macrophages and dendritic cells. Bioinformatical analysis identified IL-12p35, a subunit of the pro-inflammatory cytokine IL-12, as a potential target of $\mathrm{miR}-21$ and decreased expression of IL-12p35 was observed in the allergic asthma models. Overexpression of miR-21 alongside a luciferase reporter vector containing the 3'UTR of IL12 p35 in HEK293T cells decreased luciferase activity compared to controls, confirming IL-12p35 as a target of miR-21 [18]. A recent study by Sheedy et al. [19] identified miR-21 as a negative regulator of TLR4 signalling through its targeting of the tumour suppressor PDCD4. PDCD4 was previously shown to be a miR-21 target [20]. The authors showed that PDCD4 plays a role in pro-inflammatory signalling as PDCD4-deficient mice are protected from LPS lethality. Further investigation of this effect showed that $\mathrm{PDCD} 4$ is a positive regulator of $\mathrm{NF \kappa B}$ activation, as siRNA-mediated knock-down of PDCD4 decreased LPS-stimulated NFKB activation and PDCD4deficient bone marrow-derived macrophages (BMDMs) had impaired JNK activation and IL-6 expression. PDCD4 was also shown to negatively regulate the production of the anti-inflammatory cytokine IL-10. The mechanism here is likely to be due to the ability of PDCD4 to prevent translation of IL-10 mRNA. Murine macrophages transfected with siRNA to PDCD4 had increased production of LPS-stimulated IL-10. LPS stimulation initially increases PDCD4 expression but over time PDCD4 expression is profoundly inhibited. Correspondingly, miR-21 was induced by LPS stimulation in a number of cell types. The authors investigated if LPS-stimulated decrease in PDCD4 was due to miR-21 upregulation. Transfection of RAW264.7 cells with an anti-sense nucleotide specific to miR-21, which inhibits miR-21 activity, prevented LPS-induced PDCD4 protein level decrease. The specific link between miR-21 and PDCD4 was further il- 
lustrated when the authors showed that a morpholino oligonucleotide that specifically binds to the miR-21 target site in the 3'UTR of the PDCD4 gene also prevented LPSinduced PDCD4 protein degradation. Furthermore, the effect of PDCD4 on NFKB and IL-10 was regulated by miR-21. Overexpression of miR-21 increased LPS-stimulated IL-10 production and decreased NFKB activation, whereas inhibition of miR-21 decreased IL-10 production and increased $\mathrm{NF \kappa B}$ activation.

miR-132

A study by Shaked et al. [21] identified a novel role for miR-132 in the negative regulation of inflammation. In the presence of pro-inflammatory cytokines, vagus nerve fibres release the neurotransmitter acetylcholine (Ach). Ach inhibits NFкB activity, thereby decreasing pro-inflammatory cytokine production and helping to restore immune homeostasis. This negative feedback pathway is known as the cholinergic reflex and has been shown to be influential in a number of inflammatory diseases including a model of septic peritonitis [22]. Ach is hydrolysed by acetylcholinesterase (AChE), thus AChE can turn off the cholinergic anti-inflammatory response. The authors postulated that $\mathrm{AChE}$ levels might be regulated by miRNA. They initially showed that LPS stimulation of murine splenocytes decreased AChE mRNA, protein and activity levels whilst IL- 6 and IL- $1 \beta$ levels were significantly increased. Using an in-house spotted microarray, the authors identified two miRNA complementary to the $3^{\prime} \mathrm{UTR}$ of AChE. The expression of these two miRNA, miR-132 and miR-182*, were upregulated in response to LPS stimulation.

This correlation between LPS-inducible decrease of $\mathrm{AChE}$ and increase of miR-132 was investigated in vivo by using a modified oligonucleotide to specifically block miR-132 expression. Anti-132-treated mice had increased AChE activity in the intestine, serum and bone marrow. The authors then further link AChE and miR-132 by showing that $\mathrm{CHO}$ cells transfected with an AChE expression vector containing a mutated $3^{\prime} \mathrm{UTR}$, to which miR-132 cannot bind, have increased AChE activity compared to a control vector containing a normal UTR. They also show that overexpression of miR-132 in BMDMs decreased AChE activity by $60 \%$. In further in vivo studies the authors used TgR transgenic mice that have an AChE gene missing the miR-132 target sequence. They show that intestinal explants from these mice have both increased AChE activity and basal levels of IL-1 $\beta$, IL- 6 and IL-10. This increase in cytokine levels was ameliorated by the ACh receptor agonist nicotine, which demonstrated the effect was not due to a defect in ACh signalling. Macrophages from both wild-type and $\mathrm{TgR}$ transgenic mice that were stimulated with LPS produced pro-inflammatory cytokines. However, when ACh was added with LPS the cytokine response was decreased in wildtype BMDMs but there was no effect on the $\mathrm{TgR}$ response. The immune response of the $\mathrm{TgR}$ transgenic mice is clearly deregulated, highlighting the key role of miR-132 in regulating $\mathrm{AChE}$ activity and thus the cholinergic anti-inflammatory response [21].

\section{Regulation of TLR Signalling by Splice Variants}

Individual genes can encode multiple proteins through the expression of alternatively spliced mRNAs. As illustrated in figure 2, splice variants of a number of components of the TLR signalling pathway have been implicated as negative regulators.

\section{$M y D 88 s$}

MyD88s is a short form of myeloid differentiation primary-response protein 88 (MyD88) that does not contain the interdomain. MyD88s can bind to MyD88 and IRAK1, but overexpression of MyD88s inhibited LPS and IL-1 stimulated NFKB activation [23]. MyD88s lacks a C-terminal extra helix that is required for interaction with IRAK4 [24]. Thus, in MyD88/MyD88s heterodimers IRAK1 is not phosphorylated and downstream signalling to $\mathrm{NF \kappa B}$ activation is inhibited [25]. However, overexpression of MyD88s can activate MAPK and activator protein 1 (AP-1) transcription factor [26]. Interestingly, monocytes from septic patients express more MyD88s than healthy controls [27].

\section{IRAK2c}

In the mouse, alternative splicing of the IRAK2 gene has generated 4 isoforms of IRAK2, namely IRAK2a, IRAK2b, IRAK2c and IRAK2d [28]. There are no splice variants in humans. Overexpression of IRAK2c and IRAK2d inhibited LPS-stimulated NFKB reporter gene activation in 3T3 cells. LPS stimulation induced the expression of IRAK2c in RAW264.7 cells suggesting a possible role for IRAK2c as negative feedback regulator of TLR signalling [28]. A recent study by Conner et al. [29] has confirmed that IRAK2c is a negative regulator of TLR signalling. The authors found that macrophages from the wild-derived mouse strain MOLF/Ei had increased p38

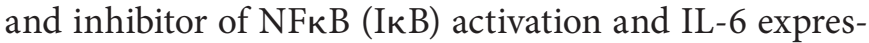
sion in response to TLR2 stimulation relative to C57BL/6J 


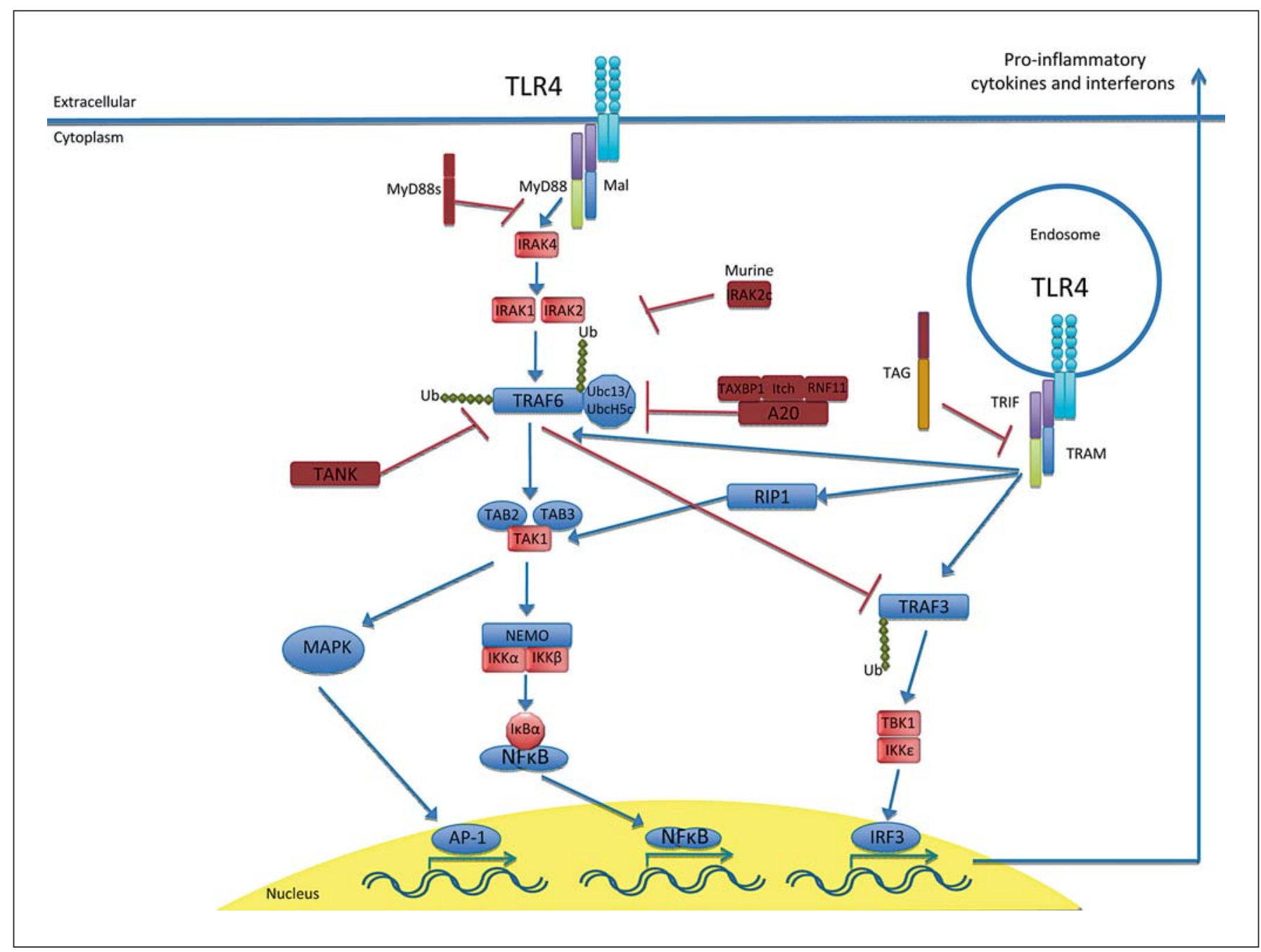

Fig. 2. Regulation of TLR signalling by splice variants and ubiquitiation. Upon stimulation, TLR4 is internalised into endosomes where it interacts with the bridging adaptor TRIF-related adaptor molecule (TRAM), which binds TIR-domain-containing adaptor protein inducing IFN- $\beta$ (TRIF). TRIF-dependent NFкB activation is mediated by TRAF6 and receptor interacting protein 1 (RIP1), both of which activate TAK1. TRIF also activates two IKKrelated proteins, inducible IKK (IKK- $\varepsilon$ ) and TANK-binding kinase 1 (TBK1), through TRAF3. IKK- $\varepsilon$ and TBK1 activate interferon regulatory factors such as IRF3 which dimerise, translocate to the nucleus and bind interferon response elements (ISRE), resulting in the induction of type-1 interferons. A splice variant of TRAM called TRAM and GOLD domain (TAG) disrupts TRIF and TRAM interactions, thus inhibiting TRIF-dependent ISRE activation. TAG is also required for TLR4 degradation. TRIF sig- nalling activates TRAF3 by Lys $^{63}$-linked ubiquitination; this is necessary for IRF3 activation. MyD88-dependent signalling through TRAF6 causes Lys ${ }^{48}$-linked degradative ubiquitination of TRAF3, allowing activation of MAPK. The splice variant MyD88s inhibits MyD88 dependent signalling by binding to MyD88 and preventing the recruitment of IRAK4. In mice, MyD88-dependent signalling is also attenuated by the IRAK2 isoform IRAK2c, which can inhibit TLR-induced IL- 6 production. TANK and the ubiquitin-editing enzyme A20 affect NFKB activation through inhibiting TRAF6 ubiquitination. A20 complexes with the regulator protein Tax1-binding protein (TAXBP1) and the E3 ligases Itch and ring finger protein 11 (RNF11) and disrupts the interactions between TRAF6 and the E2 ligases Ubc13 and $\mathrm{UbcH} 5 \mathrm{c}$. 
mice. Using genetic mapping association techniques the authors identified the Whyl locus as the source of the different responses between MOLF/Ei and C57BL/6J mice. The IRAK2 gene is located in the Whyl locus and shRNAmediated knockdown of IRAK2 in MOLF/Ei BMDMs ablated TLR2-stimulated IL- 6 production. Further analysis showed that C57BL/6J macrophages express 5- to 10-fold higher levels of IRAK2c than MOLF/Ei macrophages due to mutations in the IRAK2 promoter. The decrease in IRAK2c expression in MOLF/Ei mice renders them hyperresponsive to TLR stimulation [29]. The mechanism behind the inhibitory effect of IRAK2c is still unclear.

\section{TAG}

Palsson-McDermott et al. [30] have recently described a novel splice variant of the adaptor molecule TRIF-related adaptor molecule (TRAM), called TRAM adaptor with GOLD domain (TAG) which is involved in the negative regulation of TLR4 signalling. Confocal microscopy studies using fluorescently tagged proteins showed that upon LPS stimulation, TRAM and TLR4 move to early endosomes, they are then trafficked to late endosomes where TAG is also present. LPS stimulation of TLR4 eventually leads to lysosome-mediated degradation of TLR4, which limits downstream signalling. The authors show that TAG is required for LPS-stimulated TLR4 degradation as siRNA knockdown of TAG significantly decreased the amount of TLR4 that was degraded. Further investigations examined the role of TAG in TLR4 signalling. Overexpression of TAG inhibited LPS-stimulated activation of ISRE but not NFKB in HEK293 cells stably transfected with TLR4, CD14 and MD2. This effect was specific to TLR4 signalling as TAG had no effect on poly(I:C)-stimulated induction of ISRE and NFKB in HEK293 TLR3 cells. TLR3 recognises dsRNA from various viruses [31]. Overexpression of TRAM activated the ISRE reporter, but when TAG was co-transfected, the induction of ISRE was inhibited dose-dependently. In human PBMCs, siRNA knockdown of endogenous TAG increased LPS stimulated CCL5 (RANTES) production but did not affect IL-8 production. TRAM interacts with TIR domain-containing adaptor protein inducing IFN- $\beta$ (TRIF) for signalling to IRF3; TAG also immunoprecipitated with TRAM but not TRIF. At 40 min LPS stimulation, TRAM and TRIF no longer immunoprecipitated together while transfection of TAG also inhibited TRAM and TRIF interaction. siRNA knockdown of endogenous TAG prevented LPS-stimulated disruption of TRAM and TRIF interaction. This indicates that TAG displaces TRIF from TRAM and is required for limiting TRIF signalling in response to LPS.

\section{Regulation of TLR Signalling by Ubiquitination}

Ubiquitination has emerged as a key post-translational modification employed in the regulation of TLR signal transduction. Lys ${ }^{63}$-linked ubiquitination is required for the activation of a number of signalling molecules, whereas Lys ${ }^{48}$-linked ubiquitination results in degradation of the target protein by the $26 \mathrm{~S}$ proteasome [32]. A number of examples of ubiquitination regulation in the TLR pathway are illustrated in figure 2 .

\section{TRAF3}

TRAF3 was previously identified as playing opposing roles in TLR signal transduction. It is an important positive regulator of type-1 interferon induction but an inhibitor of pro-inflammatory cytokine production [33, 34]. Recent work by Tseng et al. [35] has explained how TRAF3 carries out its dual role in TLR signalling modulation. The authors show that TRAF3 is ubiquitinated in two distinct ways; TRIF-dependent signalling caused TRAF3 Lys ${ }^{63}$-linked self-ubiquitination, which was necessary for IRF3 activation and IFN synthesis. In contrast, MyD88-dependent signalling through TRAF6 caused the inhibition of apoptosis protein, CIAP activation and Lys $^{48}$-linked degradative ubiquitination of TRAF3, allowing MAPK activation and pro-inflammatory cytokine synthesis.

\section{TANK}

A study by Kawagoe et al. [36] identified TANK, previously characterised as a positive regulator of type- 1 interferon, as a critical negative regulator of TLR signalling. The group generated TANK-deficient mice, which developed glomerulonephritis and spontaneously began to die from 3 months old. Previous in vitro studies had implicated TANK as an adaptor molecule involved in type-1 interferon induction by both TLRs and RIG-1. However, when bone marrow-derived dendritic cells (BMDCs) from TANK-deficient mice were infected with Newcastle disease virus, they secreted similar amounts of IFN- $\alpha$ and IL- 6 compared to wild-type controls. However, when TANK-deficient macrophages were stimulated with the TLR ligands LPS, R-848, MALP-2 and CpG DNA, their secretion of TNF- $\alpha$ and IL- 6 were higher. An in vivo experiment using the TLR7 ligand R848 also showed an increase in TNF- $\alpha$ and IL- 6 secretion in TANK-deficient mice. Further investigations showed that there was increased NFкB and AP-1 transcription factor activation in R848-stimulated TANK-deficient macrophages. 
The authors show that this increased activation was not a result of increased IRAK1 activation but that TRAF6 ubiquitination in response to R848 was increased. In support of this finding, overexpression of TANK in HEK293 cells inhibited TRAF6 ubiquitination. In further studies, TANK-deficient B cells showed increased proliferation in response to mitogen stimulation. Stimulation of CD40 and $\mathrm{BCR}$ resulted in increased $\mathrm{NF \kappa} B$ activation and enhanced TRAF6 ubiquitination. In B cells, CD40 stimulation activates both the canonical NFKB and non-canonical NFкB2 pathways. Interestingly, TANK deficiency does not increase activation of the NFкB2 pathway.

\section{A20}

A20 was originally identified as an inhibitor of TNFinduced apoptosis. Since then it has been shown to be a critical negative regulator of TNF $\alpha$, IL-1 and TLR-stimulated NFKB activation [37, 38]. A20-deficient mice die prematurely as a result of severe inflammation and cachexia, which was still prevalent in mice deficient in both A20 and TNF, indicating the importance of A20 in TNFindependent inflammatory signalling. Interestingly, A20 was also shown to be protective in a model of endotoxic shock [38]. A study by Turer et al. [39] showed that the severe phenotype seen in A20-deficient mice was primarily driven by TLR signalling. When A20-deficient mice were interbred with MyD88-deficient mice the double mutant animals had remarkably increased survival rates [39]. A20 inhibits $\mathrm{TNF} \alpha$-induced $\mathrm{NF \kappa B}$ activation by modifying RIP1. A20 is a dual ubiquitin-editing enzyme, as it has both deubiquitination and ubiquitin ligase activities. A20 removes Lys $^{63}$-linked polyubiquitin chains from RIP1 and also mediates the Lys ${ }^{48}$-linked polyubiquitination of RIP1, which targets it for degradation by the proteosome [40]. In the TLR4 and IL-1R pathways, A20 inhibits $\mathrm{NF \kappa B}$ activation by inhibiting the polyubiquitination and hence the activation of TRAF6 [38].

Recently, the mechanism of A20 inhibition of TRAF6 activity was investigated by Shembade et al. [41]. Using immunoprecipitation, they compared TRAF6-binding proteins in IL-1-stimulated wild-type and A20-deficient mouse embryonic fibroblasts (MEFs). In wild-type MEFs, the A20-regulating proteins Tax1-binding protein 1 (TAX1BP1) and the E3 ubiquitin ligases ring finger protein 11 (RNF11) and Itch all associate with TRAF6. These interactions were absent in A20-deficient cells. In wildtype MEFs the E2 ubiquitin-conjugating enzymes Ubc13 and $\mathrm{UbcH} 5 \mathrm{c}$ bound to TRAF6 transiently at early time points, whereas in A20-deficient MEFs the interactions were sustained for up to $4 \mathrm{~h}$ after IL-1 stimulation. The sustained binding of Ubc13 in A20-deficient cells was also correlated with increased I $\mathrm{B} \alpha \alpha$ degradation. Ubc13 is required for Lys $^{63}$-linked ubiquitination of TRAF6, which is necessary for activation and downstream signalling. UbcH5c and TRAF6 together synthesise unanchored polyubiquitin chains that activate the ІкB kinase complex [42]. The authors also show that in IL-1-stimulated wild-type BMDCs, Ubc13 and UbcH5c are degraded at later time points whereas there is no degradation of Ubc13 and UbcH5c in A20-deficient cells. A20 can thus disrupt the interaction of TRAF6 with the E2 ligases $\mathrm{Ubc13}$ and $\mathrm{UbcH} 5 \mathrm{c}$ and may mediate their degradation during chronic stimulation of the IL-1/TLR signalling pathway [41].

\section{Regulation of NLR Family Members}

The NLR family of cytosolic PRRs contains 22 proteins in humans, the most well-studied of these being NOD1, NOD2, NLRC4 (IPAF), NLRP1 (Nalp1) and NLRP3 (Nalp3) [43]. NLR family proteins have a characteristic tri-domain structure consisting of a C-terminal leucine-rich repeat (LRR) domain, a central nucleotide binding and oligomerisation (NACHT) domain and an N-terminal effector domain. The LRR domain is thought to function in ligand recognition, although there is currently no recognised evidence for a direct interaction between NLRs and their activators. Ligand sensing through the LRR is likely to be indirect. The central NACHT domain allows oligomerisation of NLRs, which is thought to be a crucial step in their activation. The N-terminal effector domain consists of a proteinprotein interaction domain responsible for signalling $[43,44]$. This can be either a pyrin domain (PYD), a caspase recruitment domain (CARD) or a Bir domain. The NLR family can be broadly divided on this basis into subfamilies. The NLRP subfamily (NLRP1-14) contain a PYD, the NLRC subfamily (NOD1, NOD2, NLRC3 and NLRC5) contain a CARD and a third group consists of NAIP which contains a Bir domain and NLRC4 which contains a CARD $[43,44]$.

NOD1 and NOD2 Functions and Signal Transduction

NOD1 and NOD2 are two of the earliest discovered and most well-studied NLRs. Both NOD1 and NOD2 detect bacteria by sensing breakdown products of peptidoglycan, a constituent of bacterial cell walls. NOD2 recognises muramyl dipeptide (MDP) a component of peptidoglycan from most Gram-negative and Gram-positive 
bacteria, whereas NOD1 recognises meso-diaminopimelic acid (meso-DAP), which is mainly restricted to Gram-negative bacteria [44]. NOD1 and NOD2 thus recognise intracellular bacteria, bacteria that have been phagocytosed or extracellular bacteria that have secretion systems that can inject peptidoglycan motifs into the cell [44]. Recently, it was also shown that NOD2 recognises ssRNA [45]. Once activated, both NOD1 and NOD2 oligomerise and engage with the serine/threonine kinase RIP2 (RICK or CARDIACK) though their CARD domains. RIP2 is ubiquitinated and interacts with TAK1, leading to the activation of NFKB and MAPKs. These signals lead to the upregulation of proinflammatory cytokines and the release of antimicrobial peptides [44]. NOD2 and RIP2 have also been shown to associate with CARD9, which is essential for NOD2 activation of MAP kinases $\mathrm{p} 38$ and JNK but not NFKB activation [46].

Bertrand et al. [47] previously identified cIAP1 and cIAP2 as Lys ${ }^{63}$ E3 ubiquitin ligases for RIP1 in TNFR1 signalling. They have now shown a similar role for cIAP1 and cIAP2 as the ligases responsible for RIP2 ubiquitination [47]. BMDMs from cIAP1 and cIAP2 null mice were shown to have profoundly defective NFKB and MAPK activation in response to MDP and consequently a very limited cytokine response [47]. Krieg et al. [48] propose a role for XIAP. They show that XIAP interacts with RIP2 and that XIAP-deficient epithelial cells have impaired NFKB activation and IL-8 production in response to NOD1 and NOD2 ligands [48]. As the two studies were carried out in different cell types there may be functional redundancy between cIAP1/2 and XIAP.

The NOD proteins can also function independently of RIP2 and NFKB signalling. Travassos et al. [49] demonstrate that NOD1 and NOD2 directly interact with the autophagy regulator ATG16L1. Upon ligand sensing, NOD1 and NOD2 recruit ATG16L1, which initiates the autophagy of invading bacteria such as Shigella flexneri. Lipinski et al. [50] recently described a role for NOD2 in reactive oxygen species (ROS) generation. They show that NOD2 directly interacts with DUOX2, an NAD $(\mathrm{P}) \mathrm{H}$ oxidise family member that generates ROS such as $\mathrm{H}_{2} \mathrm{O}_{2}$. This interaction results in the generation of ROS which conferred protection from a Listeria monocytogenes infection model and could potentially function in downstream signalling [50]. ROS can activate the NLRP3 inflammasome [51]. Thus, this may be a mechanism of signalling crosstalk between these NLRs.
Negative Regulators of NOD1 and NOD2 Signalling

As illustrated in figure 3, a number of proteins have been described that can inhibit NOD1 and NOD2 signalling through direct interaction or by modulating the activation of RIP2.

\section{Caspase- 12}

A study by Saleh et al. [52] showed that in human populations there is a caspase- 12 single nucleotide polymorphism which encodes a premature stop codon resulting in a truncated protein product. Interestingly, the truncated protein has been selected in all of the Eurasian population, whereas the full-length proenzyme is restricted to populations of African descent. The study found that the single nucleotide polymorphism coding for fulllength caspase- 12 conferred hyporesponsiveness to LPS and had an increased frequency in a study of AfricanAmericans with severe sepsis. Another study by the same group found that caspase-12-deficient mice were resistant to peritonitis and septic shock. They also showed that caspase-12 interacted with caspase- 1 and inhibited IL-1 $\beta$ secretion but that this was independent of caspase-12 catalytic activity [53]. Recently, caspase-12 was also shown to modulate NOD1 and NOD2 signalling [54]. Caspase-12 associated with RIP2 and inhibited TRAF6 activation in response to MDP and meso-DAP, thereby attenuating antimicrobial responses [54]. However, the role of caspase- 12 in both caspase-1 and RIP 2 modulation has been questioned by a recent study of immune responses in an African population. In this study the authors found no difference in cytokine responses between individuals with different caspase-12 genotypes [55].

NOD2-s

A splice variant of NOD2 known as NOD2-s has been recently described. NOD2-s is a truncated form of NOD2 that essentially only contains a CARD [56]. NOD2-s expression is increased by IL-10 stimulation in THP-1 cells. NOD2-s was shown to negatively regulate NOD2-stimulated NFKB activation by interacting with RIP2 and disrupting NOD2 oligomerisation [56].

\section{Centaurin $\beta 1$}

Centaurin $\beta 1$ (CENTB1) is a GTPase-activating protein that was shown to interact with NOD1 and NOD2 [57]. CENTB1 can be induced by pro-inflammatory stimuli including NOD ligands. Overexpression of CENTB1 inhibited NOD1 and NOD2-dependent $\mathrm{NF} \kappa \mathrm{B}$ activation but did not affect TLR-dependent NFKB activation [57]. 


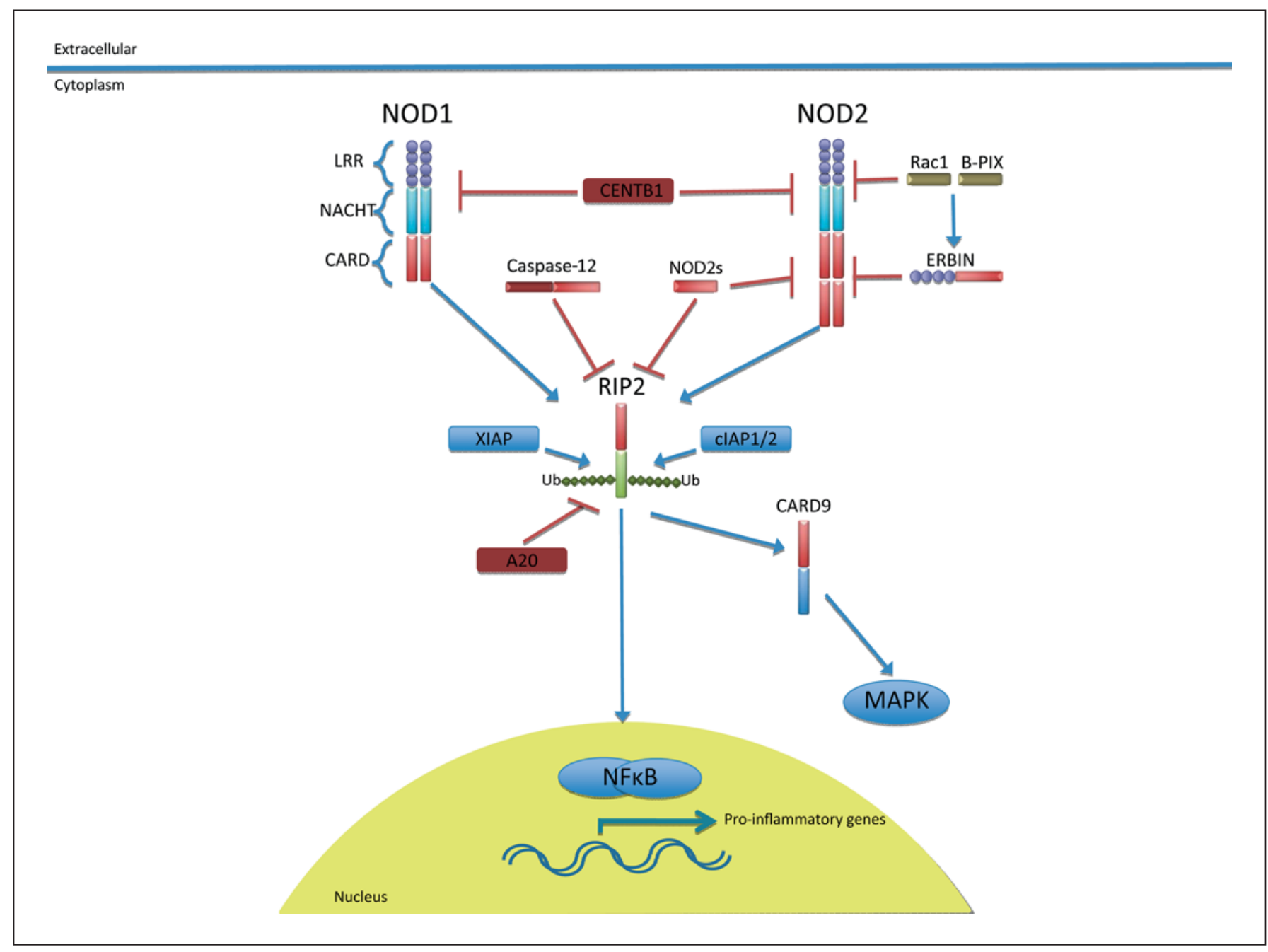

Fig. 3. Regulation of NOD1 and NOD2 signalling. NOD1 and NOD2 contain a C-terminal leucine rich repeat (LRR) domain, a central nucleotide binding and oligomerisation (NACHT) domain and $\mathrm{N}$-terminal caspase recruitment domains (CARDs). Upon activation NOD1 and NOD2 engage the serine/threonine kinase RIP2. RIP2 is ubiquitinated by the E3 ligase inhibitor of apoptosis proteins (IAPs) cIAP1, cIAP2 and XIAP. RIP2 signalling activates NFKB and MAPKs leading to the upregulation of pro-inflammatory cytokines. NOD2 and RIP2 also associate with CARD9, an essential step for NOD2 activation of MAPKs. Centaurin $\beta 1$ (CENTB1) interacts with NOD1 and NOD2 and inhibits NFKB activation. In addition, the LRR domain of Erbin inter-

Erbin

Erbin is a specific regulator of NOD2 signalling. Erbin contains a LRR domain that interacts with the CARD of NOD2. Overexpression of Erbin inhibits NOD2-dependent NFкB activation, whereas Erbin-deficient MEFs were hypersensitive to MDP stimulation acts with the CARD of NOD2 and inhibits NFKB activation. Rho family GTPase Rac1 and $\beta$-PIX (p21-activated kinase-interacting exchange factor) both interact with NOD2 attenuating NOD2dependent $\mathrm{NF \kappa} B$ activation. Racl and $\beta$-PIX may also be required for the interaction of NOD2 and Erbin. NOD2s is a splice variant of NOD2, which functions to inhibit NFKB activation by interacting with RIP2 and disrupting NOD2 oligomerisation. Caspase-12 can associate with RIP2 and possibly attenuates pro-inflammatory cytokine production. The ubiquitin-editing enzyme A20 negatively regulates NOD2 signalling by mediating the deubiquitination of RIP2.

[58]. A study by Eitel et al. [59] implicated the Rho family GTPase Rac1 as a negative regulator of NOD2 signalling. Racl was previously shown to play a positive role in TLR2-dependent NFкB activation. Inhibition of Rac1 enhanced MDP-stimulated IL-8 secretion and NFкB activation in HEK293 cells. Racl and its activator the gua- 
nine nucleotide exchange factor $\beta$-PIX (p21-activated kinase-interacting exchange factor) both interact with NOD2 and were shown to mediate NOD2 translocation to the plasma membrane in response to MDP stimulation in THP-1 cells. Inhibition of Racl disrupted the interaction of NOD2 and Erbin. Thus, Rac1 and $\beta$-PIX may be required for the negative regulation of NOD2 by Erbin [59].

\section{A20}

As previously described above, A20 is an ubiquitinediting enzyme that modulates the proteins RIP1 and TRAF6 in TLR signalling. Hitotsumatsu et al. [60] show that A20 is also a negative regulator of NOD2 signalling. A20-deficient BMDCs secrete increased levels of IL-1 $\beta$ and IL- 6 in response to MDP stimulation. BMDMs from mice triply deficient in A20, MyD88 and TRIF also had enhanced NFKB activation compared to controls that expressed A20, which ruled out any effect of TLR signalling on the response to MDP. The authors also showed that A20 mediated the deubiquitination of Lys ${ }^{63}$-ubiquitinated RIP2, which inhibited downstream signalling to NFKB [60].

\section{The Inflammasomes}

In addition to NOD1 and NOD2, three other NLR proteins, NLRP1, NLRP3 and NLRC4, have been the subjects of extensive research. Although their mechanisms of activation differ, all three proteins function by forming a high molecular weight complex with various accessory and effector proteins named inflammasomes in order to activate caspase-1 [61]. Procaspase-1 undergoes autocatalytic processing to subunits $\mathrm{p} 10$ and $\mathrm{p} 20$ that assemble to form active caspase-1 [43]. Caspase-1 processes the potent pro-inflammatory cy tokines IL-1 $\beta$ and IL-18 to their active forms. It also plays a role in unconventional protein secretion [62]. Thus the main function of the inflammasomes appears to be the control IL-1 $\beta$ processing. This is a key step in inflammation as IL-1 $\beta$ is a mediator of numerous cellular processes and deregulation of IL-1 $\beta$ can lead to profound morbidity [61].

The NLRP1 inflammasome consists of NLRP1, apoptosis-associated speck-like protein containing a CARD (ASC), caspase-1 and caspase-5. ASC is an adaptor protein that contains a PYD that binds NLRP1 and a CARD that binds caspase-1 [63]. NLRP1 recognises MDP and Bacillus anthracis lethal toxin. It has been shown that NOD2 is required for lethal toxin-induced IL-1 $\beta$ secretion, suggesting that NOD2 and NLRP1 may interact and form a complex with caspase-1 [64]. The NLRC4 or Ipaf inflammasome is activated by Gram-negative bacteria. NLRC4 appears to recognise flagellin, as flagellin deficient strains of Salmonella typhimurium and Legionella pneumophila cannot activate caspase-1 $[43,65]$. However, $S$. flexneri is a non-flagellated bacteria that also activates NLRC4 [65]. The NLRP3 inflammasome contains NLRP3, ASC and caspase-1. The adaptor molecule Cardinal has been shown to be capable of interacting with these inflammasomes but its physiological role is not well defined [66]. NLRP3 can be activated in response to a highly diverse range of pathogen, environmental and endogenously derived molecules. These include viral dsand ssRNA, fungi, bacterial MDP and pore-forming toxins such as nigericin, maitotoxin and listeriolysin, particulates such as monosodium urate crystals, alum, silica and polystyrene microparticles, fibrils such as asbestos and amyloid- $\beta$, and danger molecules such as ATP, biglycan, hyaluronan and necrotic cell lysates $[43,67,68]$.

As numerous different molecules activate the NLRP3 inflammasome, three general mechanisms of activation have been proposed. The first involves ATP stimulation of the P2X7 receptor which activates the channel protein pannexin-1. Pore formation may allow the entry of activating molecules and the release of $\mathrm{K}^{+}$from the cell which has been shown to be required for inflammasome activation. In the case of NLRP3 activation by particulates and fibrils, it is proposed that phagocytosis of these molecules can destabilise or disrupt the lysosome, releasing cathepsin B which somehow activates NLRP3, perhaps through cleaving an intermediate molecule. A third model proposes that ROS generated by 'frustrated phagocytosis' activate NLRP3 [43, 61]. Recently, Zhou et al. [69] reported that thioredoxin interacting protein (TXNIP) could bind and activate NLRP3. As ROS-induced the dissociation of TXNIP from thioredoxin, this supports a link between ROS generation and NLRP3 inflammasome activation.

Recently, a fourth inflammasome has been described which does not contain an NLR protein. Instead it contains absent in melanoma-2 (AIM2) which is a PYD containing protein of the HIN-200 family. AIM2 recognises and binds cytosolic dsDNA via the HIN200 domain and then binds ASC via the PYD; this leads to procaspase-1 activation and IL- $1 \beta$ processing. AIM2 is a broad sensor of dsDNA as it recognises viral, bacterial, mammalian and synthetic dsDNA $[43,70]$.

Inflammasome activation is a two-step process. Initially, pro-IL-1 $\beta$ mRNA synthesis is induced though $\mathrm{NF} \kappa \mathrm{B}$ activation by a primary signal. A secondary signal then activates the inflammasome and IL- $1 \beta$ release. In the case of NLRP3, the inflammasome itself also requires 
priming for action before activation by a second signal. Recently, Bauernfeind et al. [71] demonstrated that NLRP3 priming or 'licensing' can occur in response to TLR, NOD2 or TNF $\alpha$ stimulation. The authors showed that this is a primarily NFKB-dependent process and propose that NLRP3 protein expression levels are a limiting step in inflammasome activation. Franchi et al. [72] also demonstrated that $\mathrm{TNF} \alpha$ stimulation was sufficient to prime the NLRP3 inflammasome; in addition, they show that IL- $1 \alpha$ and IL- $1 \beta$ are also capable of priming. Sustained TNF $\alpha$ stimulation, unlike LPS, does not result in tolerance and an abrogated response to ATP [72]. Thus, $\mathrm{NF \kappa B}$ activation through PRRs or cytokines is a critical prerequisite for inflammasome activation and IL-1 $\beta$ release. Another recent in vitro study showed that components of the extracellular matrix, biglycan and hyaluronic acid, could prime the NLRP3 inflammasome before activation by necrotic cells [73]. These recent insights may help explain how sterile and chronic inflammation are initiated and sustained though cytokine feedback loops without pathogenic involvement.

\section{Negative Regulation of Inflammasomes}

A number of proteins modulate the CARD and PYD interactions that are central to the function of the inflammasomes. These interactions are illustrated in figure 4 .

\section{PYD-Only Proteins}

Two PYD-only proteins (POPs), POP1 and POP2, have been described. POP1 (also known as ASC2, ASCI, ASCL and PYDC1) is expressed predominantly in macrophages and granulocytes. It binds to the PYD of ASC to which it is $64 \%$ identical and may disrupt the interaction of ASC with other proteins [74]. The binding site of POP1 has recently been mapped to the $\mathrm{H} 1$ and $\mathrm{H} 4$ helices of the PYD of ASC [75]. POP2 shows closer homology to the PYDs of NLRP proteins than that of ASC. POP2 was shown to prevent the recruitment of ASC by NLRP3 [76]. A number of viruses express POP proteins that can modulate the host response; recently Rahman et al. [77] showed that a functional viral POP, MO13 from Myxoma virus inhibits $\mathrm{NF} \kappa \mathrm{B}$ activation and pro-inflammatory cytokine production through its interaction with NFKB1/p105. This protein had previously been shown to bind to ASC, which inhibited caspase- 1 activation and IL-1 $\beta$ and IL-18 secretion. Virus deficient in MO13 caused an attenuated infection and decreased dissemination compared to wild-type virus [77].

Signalling by TLRs and NLRs
CARD-Only Proteins

Several CARD-only proteins (COPs) have been shown to regulate caspase-1 activity [78]. Iceberg was the first COP to be identified; it shares $53 \%$ identity with the CARD of caspase- 1 and is induced by pro-inflammatory stimuli. Iceberg interacts with caspase-1 and inhibits LPS stimulated IL-1 $\beta$ secretion in monocytes $[79,80]$. COP-1 or pseudo-ICE is $92 \%$ similar to the CARD of caspase- 1 and also binds to caspase- 1 , preventing IL- $1 \beta$ secretion $[80,81]$. More recently, INCA (inhibitory CARD) was shown to interact with procaspase-1. INCA was upregulated by IFN $\gamma$ stimulation in monocytic cell lines and inhibited the secretion of IL- $1 \beta$ in response to LPS [82].

Interestingly, there are no murine orthologs of the POP and COP proteins. This indeed highlights the extra level of complexity involved in the regulation of NLRs in humans but provides an obstacle to the study of their functional relevance in disease.

Pyrin

The protein pyrin contains an N-terminal PYD and has been shown to inhibit or potentiate activation of the inflammasome [83]. In a study using mice that had a targeted disruption of pyrin it was found that they were hypersensitive to LPS and had enhanced caspase-1 activation and IL-1 $\beta$ secretion [84]. However, it has also been shown that pyrin can activate the inflammasome through its interaction with ASC [85]. Pyrin also contains a Cterminal SPRY (the dual-purpose splA kinase and the ryanodine receptor) domain that interacts with procaspase-1, active caspase-1, NLRP1, NLRP2, NLRP3, caspase-5 and pro-IL-1 $\beta$. These interactions inhibited caspase- 1 activation and IL- $1 \beta$ secretion $[86,87]$. Although it has not definitively been established whether pyrin acts as a negative or positive regulator of caspase- 1 activation, it is clear that pyrin plays a significant role in the regulation of IL-1 $\beta$ production. Hereditary mutations in pyrin cause the auto-inflammatory disorder familial Mediterranean fever while mutations in the pyrin interacting protein PSTPIP1 (proline serine threonine phosphatase interacting protein 1) cause another inherited autoinflammatory disorder known as PAPA (pyogenic arthritis with pyoderma gangrenosum and acne) syndrome [83].

\section{NLRP Proteins}

A number of NLRP proteins have been identified as negative regulators of inflammasome-mediated caspase- 1 activation. NLRP10 was shown to bind ASC and inhibit caspase-1 and IL-1 $\beta$ maturation [88]. NLRP7 expression was induced by LPS stimulation in THP-1 cells. 


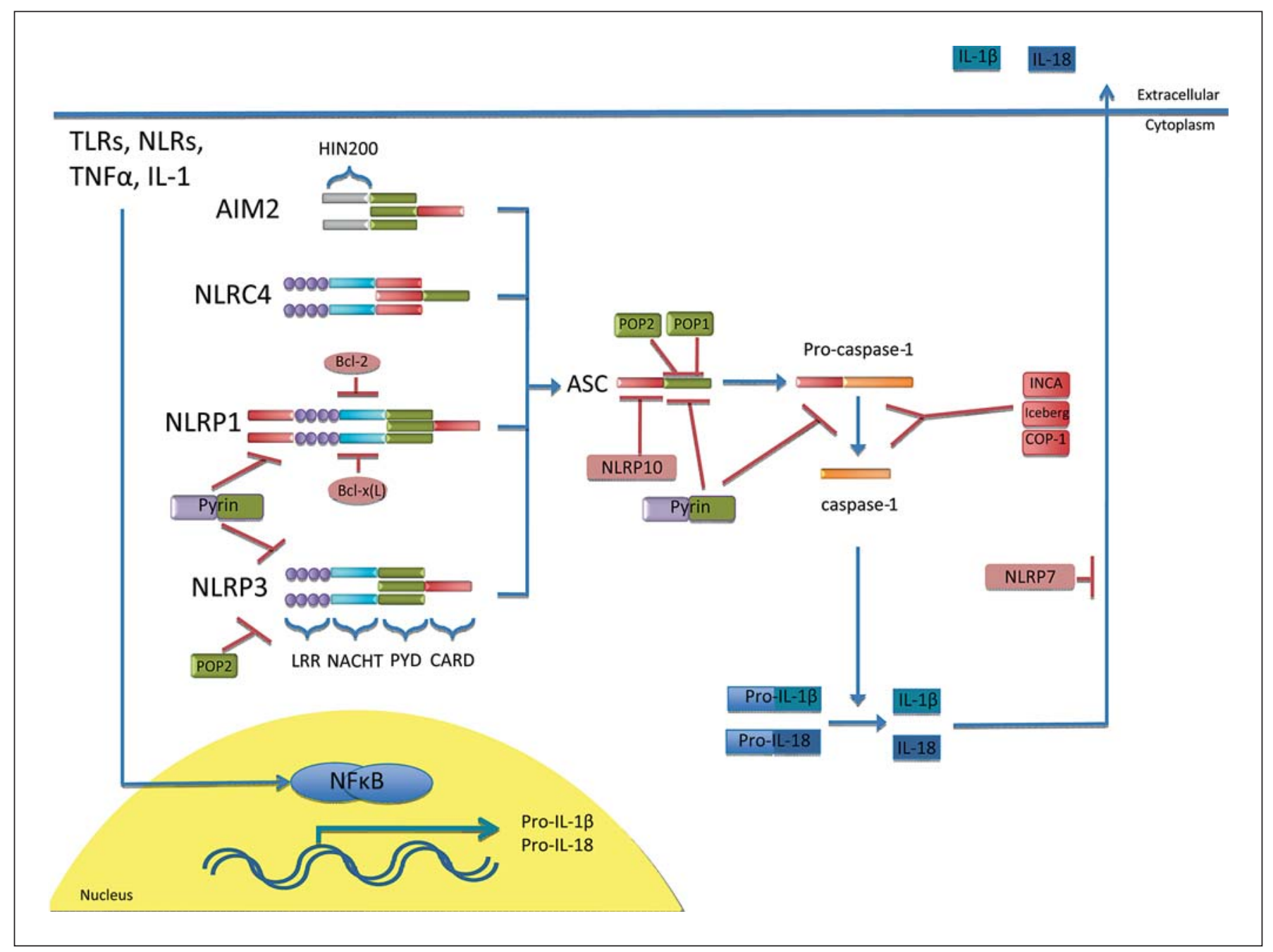

Fig. 4. Inflammasome regulation. NLRP1, NLRP3 and NLRC4 are structurally composed of LRR, NACHT, CARD and PYD, while AIM2 contains an HIN200 domain. Upon activation these molecules oligomerise and form inflammasomes with the adaptor apoptosis-associated speck-like protein containing a CARD (ASC). ASC interacts with the CARD of caspase-1, which undergoes autocatalytic processing to form active caspase-1. Activation of NFKB by TLRs, NLRs, TNF $\alpha$ or IL- 1 induces the transcription of pro-IL-1 $\beta$ and pro-IL-18. Active caspase-1 processes pro-IL-1 $\beta$ and pro-IL-18 to their active mature forms, which are secreted. The PYD only proteins (POPs) POP1 and POP2 bind to the PYD of ASC and disrupt its interactions with other proteins. POP2 pre-

While stable expression of NLRP7 in THP-1s inhibited LPS-induced IL-1 $\beta$ secretion [89].

\section{Bcl-2 and Bcl-X(L)}

The antiapoptotic proteins $\mathrm{Bcl}-2$ and $\mathrm{Bcl}-\mathrm{X}(\mathrm{L})$ have been shown to bind NALP1 [90]. This interaction abro- vents NLRP3 from recruiting ASC. The CARD-only proteins (COPs) Iceberg, inhibitory CARD (INCA) and COP-1 bind to the CARD of caspase- 1 and prevent IL-1 $\beta$ secretion. The PYD of pyrin interacts with ASC and has been shown to inhibit caspase-1 activation. However, other reports have shown that this interaction activates the inflammasome. Pyrin can also associate with caspase-1, NLRP1 and NLRP3; these interactions inhibit caspase- 1 activation and IL- $1 \beta$ secretion. NLRP10 can bind ASC and prevent caspase-1 activation. NLRP7 can inhibit IL-1 $\beta$ secretion. $\mathrm{Bcl}-2$ and $\mathrm{Bcl}-\mathrm{X}(\mathrm{L})$ are antiapoptotic proteins that interact with NLRP1 and prevent caspase-1 activation. 


\section{Conclusions}

TLR signalling is a tightly regulated process that is controlled at a number of levels. Recent research has furthered our understanding of TLR signalling at a transcriptional level where the expression of splice variants can regulate signal transduction by binding and competing with adaptor molecules. The discovery of miRNA has added a new layer of complexity to the area of post-transcriptional TLR regulation but miRNA also provide an attractive target for therapeutics. Recent studies have illustrated the key role of ubiquitination as a post-translational modification that can both positively and negatively regulate signalling molecules. NLR signalling pathways are also subject to regulation by splice variants and ubiquitination although there is currently no evidence of miRNA involvement in NLR signalling. Inflammasome activation is attenuated by numerous PYD and CARD containing proteins that interact with components of these complexes. Future studies are likely to reveal additional negative regulators of both TLRs and NLRs presenting us with both opportunities and challenges in our attempt to understand how these important receptors work in health and disease.

\section{Acknowledgement}

The work in our laboratory is funded by Science Foundation Ireland.

\section{References}

$>1$ Liew FY, Xu D, Brint EK, O’Neill LA: Negative regulation of toll-like receptor-mediated immune responses. Nat Rev Immunol 2005; 5:446-458.

2 Bartel DP: MicroRNAs: target recognition and regulatory functions. Cell 2009;136: 215-233.

3 O'Connell RM, Rao DS, Chaudhuri AA, Baltimore D: Physiological and pathological roles for microRNAs in the immune system. Nat Rev Immunol;10:111-122.

-4 O'Connell RM, Taganov KD, Boldin MP, Cheng G, Baltimore D: MicroRNA-155 is induced during the macrophage inflammatory response. Proc Natl Acad Sci USA 2007;104: 1604-1609.

5 Ruggiero T, Trabucchi M, De Santa F, Zupo S, Harfe BD, McManus MT, Rosenfeld MG, Briata P, Gherzi R: LPS induces KH-type splicing regulatory protein-dependent processing of microRNA- 155 precursors in macrophages. FASEB J 2009;23:2898-2908.

6 Ceppi M, Pereira PM, Dunand-Sauthier I, Barras E, Reith W, Santos MA, Pierre P: MicroRNA-155 modulates the interleukin-1 signaling pathway in activated human monocyte-derived dendritic cells. Proc Natl Acad Sci USA 2009;106:2735-2740.

7 Tili E, Michaille JJ, Cimino A, Costinean S, Dumitru CD, Adair B, Fabbri M, Alder H, Liu CG, Calin GA, et al: Modulation of miR155 and miR-125b levels following lipopolysaccharide/TNF- $\alpha$ stimulation and their possible roles in regulating the response to endotoxin shock. J Immunol 2007; 179:50825089.
8 Lu LF, Thai TH, Calado DP, Chaudhry A, Kubo M, Tanaka K, Loeb GB, Lee H, Yoshimura A, Rajewsky K, et al: Foxp3-dependent microRNA155 confers competitive fitness to regulatory T cells by targeting SOCS1 protein. Immunity 2009;30:80-91.

-9 Androulidaki A, Iliopoulos D, Arranz A, Doxaki C, Schworer S, Zacharioudaki V, Margioris AN, Tsichlis PN, Tsatsanis C: The kinase Akt1 controls macrophage response to lipopolysaccharide by regulating microRNAs. Immunity 2009;31:220-231.

10 Mansell A, Smith R, Doyle SL, Gray P, Fenner JE, Crack PJ, Nicholson SE, Hilton DJ, O'Neill LA, Hertzog PJ: Suppressor of cytokine signaling 1 negatively regulates Tolllike receptor signaling by mediating $\mathrm{Mal}$ degradation. Nat Immunol 2006;7:148-155.

11 O'Connell RM, Chaudhuri AA, Rao DS, Baltimore D: Inositol phosphatase SHIP1 is a primary target of miR-155. Proc Natl Acad Sci USA 2009;106:7113-7118.

12 Sly LM, Rauh MJ, Kalesnikoff J, Song CH, Krystal G: LPS-induced upregulation of SHIP is essential for endotoxin tolerance. Immunity 2004;21:227-239.

13 Taganov KD, Boldin MP, Chang KJ, Baltimore D: NF- $\mathrm{kB}$-dependent induction of microRNA miR-146, an inhibitor targeted to signaling proteins of innate immune responses. Proc Natl Acad Sci USA 2006;103: 12481-12486.

14 Hou J, Wang P, Lin L, Liu X, Ma F, An H, Wang Z, Cao X: MicroRNA-146a feedback inhibits RIG-I-dependent Type I IFN production in macrophages by targeting TRAF6, IRAK1, and IRAK2. J Immunol 2009;183: 2150-2158.
15 Tang Y, Luo X, Cui H, Ni X, Yuan M, Guo Y, Huang X, Zhou H, de Vries N, Tak PP, et al. MicroRNA-146A contributes to abnormal activation of the type I interferon pathway in human lupus by targeting the key signaling proteins. Arthritis Rheum 2009;60:10651075.

16 Nahid MA, Pauley KM, Satoh M, Chan EK: miR-146a is critical for endotoxin-induced tolerance: implication in innate immunity. J Biol Chem 2009;284:34590-34599.

17 Selcuklu SD, Donoghue MT, Spillane C: $\mathrm{miR}-21$ as a key regulator of oncogenic processes. Biochem Soc Trans 2009;37:918-925.

18 Lu TX, Munitz A, Rothenberg ME: MicroRNA-21 is up-regulated in allergic airway inflammation and regulates IL-12p35 expression. J Immunol 2009;182:4994-5002.

19 Sheedy FJ, Palsson-McDermott E, Hennessy EJ, Martin C, O'Leary JJ, Ruan Q, Johnson DS, Chen Y, O'Neill LA: Negative regulation of TLR4 via targeting of the proinflammatory tumor suppressor PDCD4 by the microRNA miR-21. Nat Immunol;11:141-147.

20 Asangani IA, Rasheed SA, Nikolova DA, Leupold JH, Colburn NH, Post S, Allgayer H: MicroRNA-21 (miR-21) post-transcriptionally downregulates tumor suppressor Pdcd 4 and stimulates invasion, intravasation and metastasis in colorectal cancer. Oncogene 2008;27:2128-2136.

21 Shaked I, Meerson A, Wolf Y, Avni R, Greenberg D, Gilboa-Geffen A, Soreq H: MicroRNA-132 potentiates cholinergic anti-inflammatory signaling by targeting acetylcholinesterase. Immunity 2009;31:965-973. 
-22 van Westerloo DJ, Giebelen IA, Florquin S, Daalhuisen J, Bruno MJ, de Vos AF, Tracey KJ, van der Poll T: The cholinergic anti-inflammatory pathway regulates the host response during septic peritonitis. J Infect Dis 2005; 191:2138-2148.

-23 Janssens S, Burns K, Tschopp J, Beyaert R: Regulation of interleukin-1- and lipopolysaccharide-induced NF- $\kappa \mathrm{B}$ activation by alternative splicing of MyD88. Curr Biol 2002; 12:467-471.

-24 Mendoza-Barbera E, Corral-Rodriguez MA, Soares-Schanoski A, Velarde M, Macieira S, Messerschmidt A, Lopez-Collazo E, Fuentes-Prior P: Contribution of globular death domains and unstructured linkers to MyD88.IRAK-4 heterodimer formation: an explanation for the antagonistic activity of MyD88s. Biochem Biophys Res Commun 2009;380:183-187.

25 Burns K, Janssens S, Brissoni B, Olivos N, Beyaert R, Tschopp J: Inhibition of interleukin 1 receptor/Toll-like receptor signaling through the alternatively spliced, short form of MyD88 is due to its failure to recruit IRAK-4. J Exp Med 2003;197:263-268.

-26 Janssens S, Burns K, Vercammen E, Tschopp J, Beyaert R: MyD88S, a splice variant of MyD88, differentially modulates NF- $\kappa B$ and AP-1-dependent gene expression. FEBS Lett 2003;548:103-107.

-27 Adib-Conquy M, Adrie C, Fitting C, Gattolliat O, Beyaert R, Cavaillon JM: Up-regulation of MyD88s and SIGIRR, molecules inhibiting Toll-like receptor signaling, in monocytes from septic patients. Crit Care Med 2006;34:2377-2385.

28 Hardy MP, O’Neill LA: The murine IRAK2 gene encodes four alternatively spliced isoforms, two of which are inhibitory. J Biol Chem 2004;279:27699-27708.

-29 Conner JR, Smirnova, II, Poltorak A: A mutation in Irak2c identifies IRAK-2 as a central component of the TLR regulatory network of wild-derived mice. J Exp Med 2009; 206:1615-1631.

-30 Palsson-McDermott EM, Doyle SL, McGettrick AF, Hardy M, Husebye H, Banahan K, Gong M, Golenbock D, Espevik T, O'Neill LA: TAG, a splice variant of the adaptor TRAM, negatively regulates the adaptor MyD88-independent TLR4 pathway. Nat Immunol 2009; 10:579-586.

-31 Kumar H, Kawai T, Akira S: Pathogen recognition in the innate immune response. Biochem J 2009;420:1-16.

- 32 Carpenter S, O’Neill LA: Recent insights into the structure of Toll-like receptors and posttranslational modifications of their associated signalling proteins. Biochem J 2009; 422:1-10.

33 Hacker H, Redecke V, Blagoev B, Kratchmarova I, Hsu LC, Wang GG, Kamps MP, Raz E, Wagner H, Hacker G, et al: Specificity in Toll-like receptor signalling through distinct effector functions of TRAF3 and TRAF6. Nature 2006;439:204-207.
4 Oganesyan G, Saha SK, Guo B, He JQ, Shahangian A, Zarnegar B, Perry A, Cheng G: Critical role of TRAF3 in the Toll-like receptor-dependent and -independent antiviral response. Nature 2006;439:208-211.

- 35 Tseng PH, Matsuzawa A, Zhang W, Mino T, Vignali DA, Karin M: Different modes of ubiquitination of the adaptor TRAF3 selectively activate the expression of type I interferons and proinflammatory cytokines. Nat Immunol 2010;11:70-75.

36 Kawagoe T, Takeuchi O, Takabatake Y, Kato $\mathrm{H}$, Isaka $\mathrm{Y}$, Tsujimura T, Akira S: TANK is a negative regulator of Toll-like receptor signaling and is critical for the prevention of autoimmune nephritis. Nat Immunol 2009;10: 965-972.

37 Coornaert B, Carpentier I, Beyaert R: A20: central gatekeeper in inflammation and immunity. J Biol Chem 2009;284:8217-8221.

38 Boone DL, Turer EE, Lee EG, Ahmad RC, Wheeler MT, Tsui C, Hurley P, Chien M, Chai S, Hitotsumatsu O, et al: the ubiquitinmodifying enzyme A20 is required for termination of Toll-like receptor responses. Nat Immunol 2004;5:1052-1060.

39 Turer EE, Tavares RM, Mortier E, Hitotsumatsu O, Advincula R, Lee B, Shifrin N, Malynn BA, Ma A: Homeostatic MyD88-dependent signals cause lethal inflammation in the absence of A20. J Exp Med 2008;205:451464.

40 Wertz IE, O’Rourke KM, Zhou H, Eby M, Aravind L, Seshagiri S, Wu P, Wiesmann C, Baker R, Boone DL, et al: De-ubiquitination and ubiquitin ligase domains of A20 downregulate NF- $\kappa$ B signalling. Nature 2004;430: 694-699.

41 Shembade N, Ma A, Harhaj EW: Inhibition of NF- $\mathrm{B}$ signaling by A20 through disruption of ubiquitin enzyme complexes. Science;327:1135-1139.

42 Xia ZP, Sun L, Chen X, Pineda G, Jiang X, Adhikari A, Zeng W, Chen ZJ: Direct activation of protein kinases by unanchored polyubiquitin chains. Nature 2009;461:114-119.

43 Bryant C, Fitzgerald KA: Molecular mechanisms involved in inflammasome activation. Trends Cell Biol 2009;19:455-464.

44 Chen G, Shaw MH, Kim YG, Nunez G: NOD-like receptors: role in innate immunity and inflammatory disease. Annu Rev Pathol 2009;4:365-398.

45 Sabbah A, Chang TH, Harnack R, Frohlich V, Tominaga K, Dube PH, Xiang Y, Bose S: Activation of innate immune antiviral responses by Nod2. Nat Immunol 2009;10: 1073-1080.

46 Hsu YM, Zhang Y, You Y, Wang D, Li H, Duramad O, Qin XF, Dong C, Lin X: The adaptor protein $\mathrm{CARD} 9$ is required for innate immune responses to intracellular pathogens. Nat Immunol 2007;8:198-205.
47 Bertrand MJ, Doiron K, Labbe K, Korneluk RG, Barker PA, Saleh M: Cellular inhibitors of apoptosis cIAP1 and cIAP2 are required for innate immunity signaling by the pattern recognition receptors NOD1 and NOD2. Immunity 2009;30:789-801.

48 Krieg A, Correa RG, Garrison JB, Le Negrate G, Welsh K, Huang Z, Knoefel WT, Reed JC: XIAP mediates NOD signaling via interaction with RIP2. Proc Natl Acad Sci USA 2009;106:14524-14529.

49 Travassos LH, Carneiro LA, Ramjeet M, Hussey S, Kim YG, Magalhaes JG, Yuan L, Soares F, Chea E, Le Bourhis L, et al: Nod1 and Nod2 direct autophagy by recruiting ATG16L1 to the plasma membrane at the site of bacterial entry. Nat Immunol;11:55-62.

50 Lipinski S, Till A, Sina C, Arlt A, Grasberger H, Schreiber S, Rosenstiel P: DUOX2-derived reactive oxygen species are effectors of NOD2-mediated antibacterial responses. J Cell Sci 2009;122:3522-3530.

51 Dostert C, Petrilli V, Van Bruggen R, Steele C, Mossman BT, Tschopp J: Innate immune activation through Nalp3 inflammasome sensing of asbestos and silica. Science 2008; 320:674-677.

52 Saleh M, Vaillancourt JP, Graham RK, Huyck M, Srinivasula SM, Alnemri ES, Steinberg MH, Nolan V, Baldwin CT, Hotchkiss RS, et al: Differential modulation of endotoxin responsiveness by human caspase-12 polymorphisms. Nature 2004;429: 75-79.

53 Saleh M, Mathison JC, Wolinski MK, Bensinger SJ, Fitzgerald P, Droin N, Ulevitch RJ, Green DR, Nicholson DW: Enhanced bacterial clearance and sepsis resistance in caspase-12-deficient mice. Nature 2006;440: 1064-1068.

54 LeBlanc PM, Yeretssian G, Rutherford N, Doiron K, Nadiri A, Zhu L, Green DR, Gruenheid S, Saleh M: Caspase-12 modulates NOD signaling and regulates antimicrobial peptide production and mucosal immunity. Cell Host Microbe 2008;3:146-157.

55 Ferwerda B, McCall MB, de Vries MC, Hopman J, Maiga B, Dolo A, Doumbo O, Daou $\mathrm{M}$, de Jong $\mathrm{D}$, Joosten LA, et al: Caspase-12 and the inflammatory response to Yersinia pestis. PLoS One 2009;4:e6870.

56 Rosenstiel P, Huse K, Till A, Hampe J, Hellmig S, Sina C, Billmann S, von Kampen O, Waetzig GH, Platzer M, et al: A short isoform of NOD2/CARD15, NOD2-S, is an endogenous inhibitor of NOD2/receptor-interacting protein kinase 2-induced signaling pathways. Proc Natl Acad Sci USA 2006;103: 3280-3285.

57 Yamamoto-Furusho JK, Barnich N, Xavier R, Hisamatsu T, Podolsky DK: Centaurin $\beta 1$ down-regulates nucleotide-binding oligomerization domains 1- and 2-dependent NF$\kappa B$ activation. J Biol Chem 2006;281:3606036070 . 
58 McDonald C, Chen FF, Ollendorff V, Ogura Y, Marchetto S, Lecine P, Borg JP, Nunez G: A role for Erbin in the regulation of Nod2dependent NF- $\kappa B$ signaling. J Biol Chem 2005;280:40301-40309.

-59 Eitel J, Krull M, Hocke AC, N'Guessan PD, Zahlten J, Schmeck B, Slevogt H, Hippenstiel S, Suttorp N, Opitz B: $\beta$-PIX and Rac1 GTPase mediate trafficking and negative regulation of NOD2. J Immunol 2008;181: 2664-2671.

-60 Hitotsumatsu O, Ahmad RC, Tavares R, Wang M, Philpott D, Turer EE, Lee BL, Shiffin N, Advincula R, Malynn BA, et al: The ubiquitin-editing enzyme A20 restricts nucleotide-binding oligomerization domain containing 2-triggered signals. Immunity 2008;28:381-390.

61 Martinon F, Mayor A, Tschopp J: The inflammasomes: guardians of the body. Annu Rev Immunol 2009;27:229-265.

-62 Keller M, Ruegg A, Werner S, Beer HD: Active caspase-1 is a regulator of unconventional protein secretion. Cell 2008;132:818-831.

63 Faustin B, Lartigue L, Bruey JM, Luciano F, Sergienko E, Bailly-Maitre B, Volkmann N, Hanein D, Rouiller I, Reed JC: Reconstituted NALP1 inflammasome reveals two-step mechanism of caspase- 1 activation. Mol Cell 2007;25:713-724.

-64 Hsu LC, Ali SR, McGillivray S, Tseng PH, Mariathasan S, Humke EW, Eckmann L, Powell JJ, Nizet V, Dixit VM, et al: A NOD2NALP1 complex mediates caspase-1-dependent IL- $1 \beta$ secretion in response to Bacillus anthracis infection and muramyl dipeptide. Proc Natl Acad Sci USA 2008; 105:78037808.

-65 Suzuki T, Franchi L, Toma C, Ashida H, Ogawa $\mathrm{M}$, Yoshikawa Y, Mimuro $\mathrm{H}$, Inohara $\mathrm{N}$, Sasakawa C, Nuñez G: Differential regulation of caspase-1 activation, pyroptosis, and autophagy via Ipaf and ASC in Shigella-infected macrophages. PLoS Pathog 2007; 3:e111.

66 Agostini L, Martinon F, Burns K, McDermott MF, Hawkins PN, Tschopp J: NALP3 forms an IL-1 $\beta$-processing inflammasome with increased activity in Muckle-Wells autoinflammatory disorder. Immunity 2004; 20:319-325.

67 Cassel SL, Sutterwala FS: Sterile inflammatory responses mediated by the NLRP 3 inflammasome. Eur J Immunol;40:607-611.

68 Cassel SL, Joly S, Sutterwala FS: The NLRP3 inflammasome: a sensor of immune danger signals. Semin Immunol 2009;21:194-198.
69 Zhou R, Tardivel A, Thorens B, Choi I, Tschopp J: Thioredoxin-interacting protein links oxidative stress to inflammasome activation. Nat Immunol;11:136-140.

70 Schroder K, Muruve DA, Tschopp J: Innate immunity: cytoplasmic DNA sensing by the AIM2 inflammasome. Curr Biol 2009; 19:R262-R265.

71 Bauernfeind FG, Horvath G, Stutz A, Alnemri ES, MacDonald K, Speert D, FernandesAlnemri T, Wu J, Monks BG, Fitzgerald KA, et al: Cutting edge: NF- $\kappa \mathrm{B}$ activating pattern recognition and cytokine receptors license NLRP3 inflammasome activation by regulating NLRP3 expression. J Immunol 2009; 183:787-791.

72 Franchi L, Eigenbrod T, Nuñez G: Cutting edge: TNF- $\alpha$ mediates sensitization to ATP and silica via the NLRP3 inflammasome in the absence of microbial stimulation. J Immunol 2009;183:792-796.

73 Iyer SS, Pulskens WP, Sadler JJ, Butter LM, Teske GJ, Ulland TK, Eisenbarth SC, Florquin S, Flavell RA, Leemans JC, et al: Necrotic cells trigger a sterile inflammatory response through the Nlrp3 inflammasome. Proc Natl Acad Sci USA 2009;106:2038820393.

74 Stehlik C, Krajewska M, Welsh K, Krajewski S, Godzik A, Reed JC: The PAAD/PYRINonly protein POP1/ASC2 is a modulator of ASC-mediated nuclear-factor- $\kappa$ B and procaspase-1 regulation. Biochem J 2003;373 101-13.

75 Srimathi T, Robbins SL, Dubas RL, Chang H, Cheng H, Roder H, Park YC: Mapping of POP1-binding site on pyrin domain of ASC. J Biol Chem 2008;283:15390-15398.

76 Bedoya F, Sandler LL, Harton JA: Pyrin-only protein 2 modulates NF- $\mathrm{KB}$ and disrupts ASC:CLR interactions. J Immunol 2007;178: 3837-3845.

77 Rahman MM, Mohamed MR, Kim M, Smallwood S, McFadden G: Co-regulation of $\mathrm{NF}-\kappa \mathrm{B}$ and inflammasome-mediated inflammatory responses by myxoma virus pyrin domain-containing protein M013. PLoS Pathog 2009;5:e1000635.

78 Stehlik C, Dorfleutner A: COPs and POPs: modulators of inflammasome activity. J Immunol 2007;179:7993-7998.

79 Humke EW, Shriver SK, Starovasnik MA, Fairbrother WJ, Dixit VM: ICEBERG: a novel inhibitor of interleukin-1 $\beta$ generation. Cell 2000;103:99-111.

80 Druilhe A, Srinivasula SM, Razmara M, Ahmad M, Alnemri ES: Regulation of IL-1 $\beta$ generation by Pseudo-ICE and ICEBERG, two dominant negative caspase recruitment domain proteins. Cell Death Differ 2001;8 649-657.
81 Lee SH, Stehlik C, Reed JC: Cop, a caspase recruitment domain-containing protein and inhibitor of caspase-1 activation processing. J Biol Chem 2001;276:34495-34500.

82 Lamkanfi M, Denecker G, Kalai M, D’Hondt K, Meeus A, Declercq W, Saelens X, Vandenabeele P: INCA, a novel human caspase recruitment domain protein that inhibits interleukin-1 $\beta$ generation. J Biol Chem 2004; 279:51729-51738.

83 Chae JJ, Aksentijevich I, Kastner DL: Advances in the understanding of familial Mediterranean fever and possibilities for targeted therapy. Br J Haematol 2009; 146:467478

84 Chae JJ, Komarow HD, Cheng J, Wood G, Raben N, Liu PP, Kastner DL: Targeted disruption of pyrin, the FMF protein, causes heightened sensitivity to endotoxin and a defect in macrophage apoptosis. Mol Cell 2003; 11:591-604.

85 Yu JW, Wu J, Zhang Z, Datta P, Ibrahimi I, Taniguchi S, Sagara J, Fernandes-Alnemri T, Alnemri ES: Cryopyrin and pyrin activate caspase-1, but not NF- $\kappa$ B, via ASC oligomerization. Cell Death Differ 2006;13:236-249.

86 Chae JJ, Wood G, Masters SL, Richard K, Park G, Smith BJ, Kastner DL: The B30.2 domain of pyrin, the familial Mediterranean fever protein, interacts directly with caspase-1 to modulate IL-1 $\beta$ production. Proc Natl Acad Sci USA 2006;103:9982-9987.

87 Papin S, Cuenin S, Agostini L, Martinon F, Werner S, Beer HD, Grutter C, Grutter M, Tschopp J: The SPRY domain of Pyrin, mutated in familial Mediterranean fever patients, interacts with inflammasome components and inhibits proIL-1 $\beta$ processing. Cell Death Differ 2007;14:1457-1466.

88 Wang $\mathrm{Y}$, Hasegawa M, Imamura R, Kinoshita T, Kondo C, Konaka K, Suda T: PYNOD, a novel Apaf-1/CED4-like protein is an inhibitor of ASC and caspase-1. Int Immunol 2004;16:777-786.

89 Kinoshita T, Wang Y, Hasegawa M, Imamura R, Suda T: PYPAF3, a PYRIN-containing APAF-1-like protein, is a feedback regulator of caspase-1-dependent interleukin- $1 \beta$ secretion. J Biol Chem 2005;280:21720-21725.

90 Bruey JM, Bruey-Sedano N, Luciano F, Zhai D, Balpai R, Xu C, Kress CL, Bailly-Maitre B, LiX, Osterman A, et al: Bcl-2 and Bcl-XL regulate proinflammatory caspase-1 activation by interaction with NALP1. Cell 2007;129: $45-56$. 